Original scientific paper

UDK: 655.3.022.3

\title{
Changes in the surface roughness of aluminium oxide (non-printing) areas on off set printing plate depending on number of imprints
}

\author{
Authors: Živko Pavlović ${ }^{1}$, Dragoljub Novaković ${ }^{1}$, Sandra Dedijer ${ }^{1}$, Magdolna Apro ${ }^{1}$ \\ ${ }^{1}$ Faculty of technical sciences, Graphic Engineering and Design, Novi Sad, Serbia
}

\begin{abstract}
A printing and non-printing surface structure of the offset printing forms are key factors in maintaining the conventional offset printing. The main characteristics of the surface are: physical and chemical structure, surface tension and surface roughness. Surface topography is one of the critical factors which could cause the instability in the quality performance and the durability of the printing forms. During the printing process these characteristics change and directly influence the print. Performed investigations are based on the fact that the changes in physicalchemical properties of the non-printing areas as well as the changes in the surface micro structure of the printing forms directly influence the quality of the reproduction. In this paper, the behaviour of non-printing elements of a thermal CTP plate developed in a fresh developer and used for a print run of 123.000, 177.000 and 300.000 copies on a web offset heat-set printing press has been investigated. Investigation made in a paper showed that high depth of focus SEM (Scanning Electron Microscope) can provide detailed topographical information about the surface, but cannot provide quantitative topographical information. Due to this fact, the printing forms have been also observed and analysed before and after the print run by a mechanical stylus profilometer. The investigations reveal the appearance of the physical changes as well as the geometrical ones. As a result of these changes, the influence of a fountain solution on the printing form may also vary, as well as the balance between the ink and the fountain solution during the printing process.
\end{abstract}

Keywords: Non-printing surface, surface roughness, thermal printing plates, print run

\section{Introduction}

The functional properties of materials used in many engineering industries are often determined by the surface structure and its characteristics. The topography characterization is very important for many applications since the roughness of the surface is a significant engineering factor (Dimogerontakis et al., 2006). Example of surfaces with asymmetric roughness, where the topography characterization is one of the most important engineering factors, is the aluminium printing forms used for lithographic applications. The production of aluminium plates for offset printing involves roughen-

First received: 25.07.2010.

Accepted: 24.09.2010 ing of the aluminium substrate in order to increase the surface area, necessary to improve the adhesion of the photosensitive coating and to enhance the water retentive properties of the aluminium surface (Brinkman and Kernig, 2003).

Aluminium surface prepared for use as an offset printing plate consist of two different areas: ink-receptive image areas coated with a photosensitive layer and aluminium oxide and fountain solution retaining non-printing areas. In order to improve the fountain solution adhesion on the aluminium oxide film and to enhance the adhesion of the photosensitive coating during the printing process (Dimogerontakis et al, 2006) the foil needs to be roughened by electrochemical graining and anodic oxidation (Mahovic Poljacek et al., 2007). 
Stability and surface definition is an important part in the processes of production and processing of printing forms. The typical steps in printing plate manufacturing consists of: cleaning, graining, anodisation, post anodic treatments, coating with a photosensitive layer, optionally followed by a baking process for hardening the coating. In cleaning, usually an alkaline etching, residual contaminations and the natural oxide skin of the aluminium surface are removed. In graining the aluminium surface is roughened to a well-defined topography. Nowadays electro-chemical graining (EC-graining) has replaced mechanical graining due to the finer and more defined topographies that can be obtained with the former. EC-graining is performed in acidic electrolytes, based on either hydrochloric acid or nitric acid. The surface topography after EC-graining consists of hemispherical pit-type craters with depths in the order of $2 \mu \mathrm{m}$ to $10 \mu \mathrm{m}$, and is needed to ensure a good adhesion of the coating and to improve the water retentive properties of the surface. In anodisitation phase freshly formed surface is mechanically and chemically stabilized with a contour sensitive anodic film of approximately $1 \mu \mathrm{m}$ thick. Post anodic treatments differ between manufacturers but generally serve to improve the hydrophilicity of non-printing areas (Brinkman and Kernig, 2003).

Due to the fact that aluminium oxide layer on the printing plates is a thin and extremely porous and that standardized plate making process requires immersing of the plate in the alkaline solution, significant changes in the structure occurred during the immersion. These changes are the consequence of the amorphous properties of aluminium oxide that is soluble in different alkaline solutions (Mahovic Poljacek et. al, 2008a).

The aim of this study was to determine the influence of print run on aluminium oxide areas. Therefore, analyses of the changes of a surface topography on non-printing areas of the printing form using standard profilometric method as well as SEM micrographs for quantitative and qualitative characterization have been made. For this purpose we have used one type of lithographic printing plate with uniform surface structures and roughness of the non-printing (aluminium oxide) areas. Selection was motivated by the reason that size and quality of the grained surface microstructure influence the printing performance and durability of the printing plates (Hutchinson, 2001). They are manufactured according to stringent, standardized procedures (ISO 12218:1997, 2004) resulting in surfaces of controlled and reproducible roughness suitable for the purpose of this study.

\section{Materials and methods}

The lithographic printing plates used in this study are thermal positive printing plates of $0.3 \mathrm{~mm}$ thick AA1050 aluminium foil electrochemically roughened and anodized. As it was already mentioned aluminium surface of used offset printing plate consists of two different areas: ink-receptive (oleophilic) image areas, which carry a photosensitive coating and fountain solution (hydrophilic) retaining non-image areas.

The plates have been exposed by same laser sensitivity or exposure energy of approximately $140 \mathrm{~mJ} / \mathrm{cm}$. After the exposition the photosensitive layer was removed from exposed (non-printing) areas of the plate.

The removal has been achieved by chemical processing in alkaline Kodak Goldstar premium developer. The developing process has been made according to the standardized processing procedure: at the temperature of processing solution of $22 \pm 3{ }^{\circ} \mathrm{C}$, processing speed in the range of $0,7-1,2 \mathrm{~m} / \mathrm{min}$ and the processing time of 18 \pm 4 s.

In this study the measurements were made at five distinct circular sample areas from the same non-printing area of the printing plate sample $(R=1.5 \mathrm{~cm})$, positioned along the line of printing pressure in the printing units and with center-to-center interval of $20 \mathrm{~cm}$.

The profilometric measurements were made at unused printing plate sample and on samples taken after a print run of 123,000, 177,000 and 300,000 impressions. Print runs were done on four colour printing machine with four basic printing colours in following sequence: black, cyan, magenta and yellow. For each colour a single printing plate was used. For this investigation we have used the data obtained from measurements on printing plates from second and last printing unit. Second printing unit has contact with paper which has small amount of dust and other substances used on first printing unit: ink, fountain solution, etc. The choice of the last printing unit was due to changes in plate surface roughness encompass all possible influences beside the printing pressure (e.g. paper dust, ink residuals etc.).

It is important to note that the printing ink has no influence on measurement results, when measurements were performed on samples from aluminium oxide - nonprinting areas.

The SEM micrographs of the samples were made by JEOL JSM 6460 LV scanning electron microscope. To assure the uniform electrical properties and to avoid the charging/discharging of aluminium oxide surfaces, the printing plates samples $(R=1.5 \mathrm{~cm})$ were gold coated by ion sputtering $\left(15.0 \mathrm{~nm}\right.$ thick, density $\left.19.32 \mathrm{~g} / \mathrm{cm}^{3}\right)$. The images were taken at working distance of $15 \mathrm{~mm}$ at voltage $20 \mathrm{kV}$ with magnification 2000x and 5000x.

The profilometric parameters were measured with the Portable Surface Roughness Tester TR200 (Anon, 2009) provided with a diamond tip with $2 \mu \mathrm{m}$ radius. The TR200 is capable of evaluating different roughness parameters: $R_{a}, R_{z}, R_{y}, R_{q}, R_{t}, R_{p}, R_{\max }, R_{m}, R_{3 z}, S, S_{m^{\prime}}, S_{k^{\prime}}$ tp, and hybrid parameters: primary profile $(P)$, roughness profile $(R)$, and $t p$ curve (material ratio $M_{r}$ ), all defined according to the pertinent ISO standards (ISO 4287:1997 and ISO 12218:1997, 2004). 
The relevant measurement's parameters were: sampling length: $0.80 \mathrm{~mm}$, traversing speed: $V_{\mathrm{t}}=0.135 \mathrm{~mm} / \mathrm{s}$, measuring range: $\pm 20 \mu \mathrm{m}$ and resolution: $0.01 \mu \mathrm{m}$.

The measured surface roughness parameters used in this study are compliant to the geometric product specification standards (ISO 4287:1997 and ISO 12218:1997, 2004) and listed below:

- $R_{a}$ - average surface roughness:

$$
R_{a}=\frac{1}{l} \int_{0}^{1}|y(x)| d x
$$

- $R_{\mathrm{q}}$ - root-mean-square deviation $\left(\mathrm{R}_{\mathrm{ms}}\right)$ :

$$
R_{q}=\sqrt{\frac{1}{l}} \int_{0}^{1} y^{2}(x) d x
$$

- $R_{z D I N}$ - mean value of the single roughness depths $Z_{i}$ :

$$
R_{z D I N}=\frac{1}{n}\left(Z_{1}+Z_{2}+\ldots+Z_{n}\right)
$$

- $R_{\mathrm{p}}$ - leveling depth, distance between highest peak and the reference line.

To make aluminum suitable for making printing forms, plate is processed by rolling procedure, which results in the characteristic structure of the surface in the direction of rolling. Lines that occur on the surface are not desirable in the further preparation of aluminum and require special treatment to reduce their negative impact on the surface roughness. Processing of aluminum includes the processes of electrochemical surface roughening and anodic oxidation as it was mentioned earlier, which produces aluminum surface microstructure of porous aluminum oxide (Mahovic Poljacek et al., 2007).

Therefore, the measurement of surface roughness of the printing forms are carried in $\mathrm{x}$ and $\mathrm{y}$ direction, i.e. in the direction of aluminum rolling and perpendicular to the direction of rolling.

Since the investigation made by Mahovic Poljacek and others (2008b) showed that high depth of focus SEM can provide detailed topographical information about the surface, but cannot provide quantitative topographical information, we have observed and analysed printing plates, before and after print run by a roughness meter (Time Group TR200) and by a SEM and thus combined the quantitative topographical information and the micrographs obtained by the SEM.

\section{Results and discussion}

\section{SEM analysis}

The SEM micrograph presented in Figure 1.a shows the structure of aluminium oxide surface of the reference - unused sample of printing plate. The surface of unused sample of printing plate is characterized with high narrow peaks and deep and narrow pores. One can see uneven rough microstructure surface as the result of specific electrochemical graining conditions during the production process. This microstructure of aluminium oxides layer indicates good adhesion of the wetting solution during the printing process. Aluminium oxide is very reactive and during anodisation it can form layer on both sides of a single printing plate with irregular surface structure.
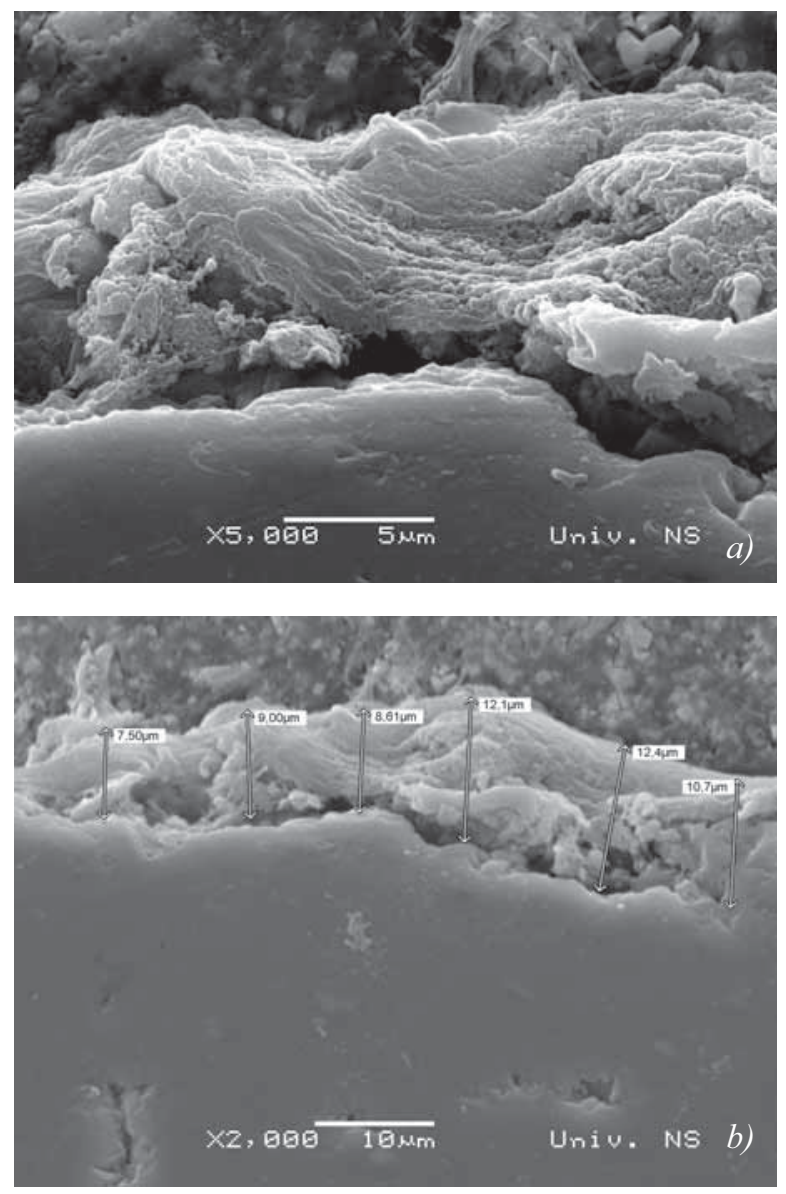

Figure 1. SEM micrograph - cross section of aluminium oxide layer on unused printing plate a) magnification of $5000 x$

b) magnification of 2000x with thickness measures of aluminium oxide layer

On Figure 1.b) one can see measured height of aluminium oxide layer. As Brinkman and Kernig (2003) found, height of aluminium oxide pores can vary from $2 \mu \mathrm{m}$ to $10 \mu \mathrm{m}$. On the SEM micrograph measured height vary from 7,5 $\mu \mathrm{m}$ to $12,4 \mu \mathrm{m}$. These results might be consequence of uneven grained rough surface of the printing plate and different referent point for every measure. This micrograph samples show a changeable structure of aluminium oxide of unused printing plate which can cause a different behavior of surface structure related to wetting of non-printing elements during printing process.

Figure 2 represents SEM micrographs of surface topography of unused printing plate sample and printing plate samples after 123.000 impressions and the changes in 
surface topography of printing plates can be clearly seen. Changes are manifested as lowering of the peaks and flattening of the "valleys".
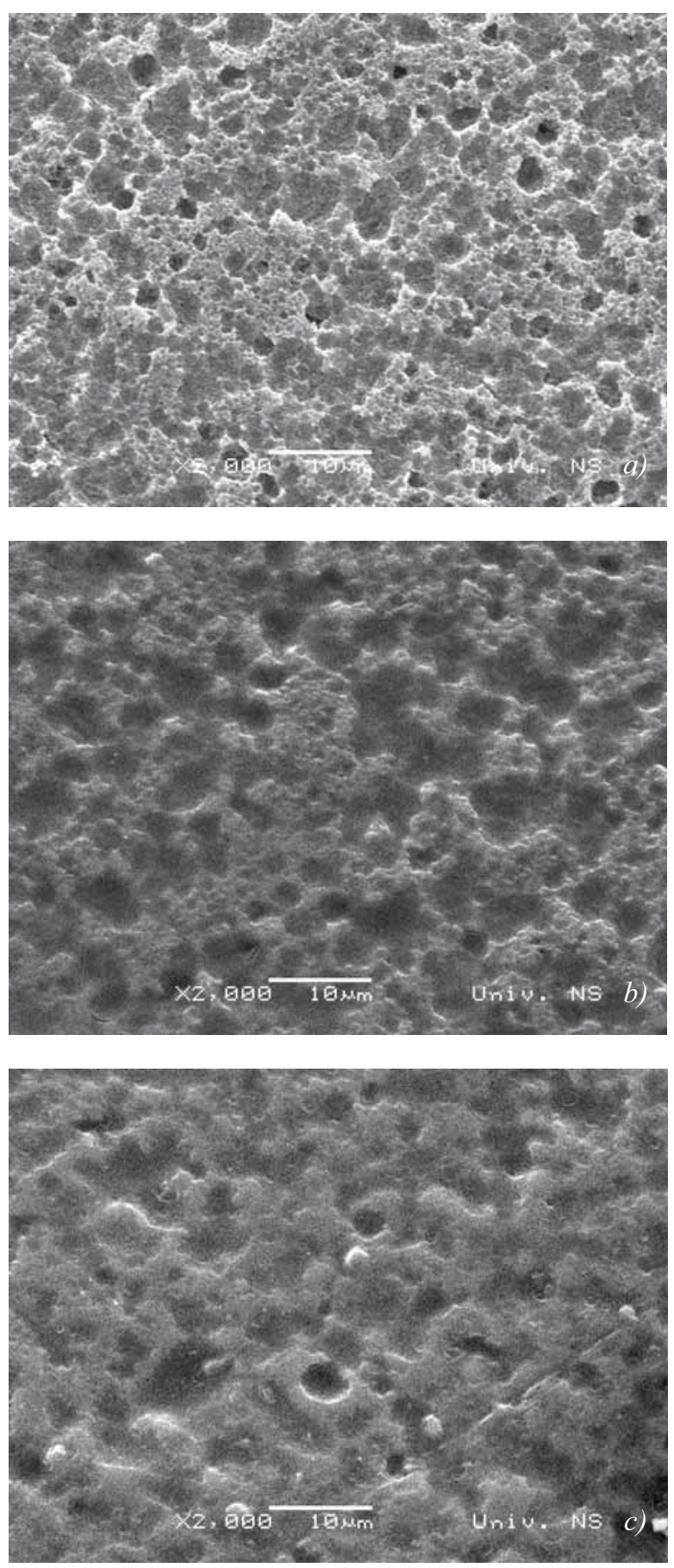

Figure 2. SEM micrograph of a) unused printing plate sample, and samples after 123.000 impressions of

b) printing plate for cyan colour and c) printing plate for yellow colour

SEM micrographs presented in Figure 3 show changes in surface topography of used printing plates samples after 177.000 impressions. If we compare it with SEM micrographs shown of Figure 2, it is evidently that these samples have major changes of surface topography reflected in broader peaks and shallower and broader "valleys". These changes are more obvious on the mi- crograph b) (Figure 3) sample of printing plate for yellow and they are expected since this plate is from last printing unit where it has higher pressure influenced by serial parameters (accumulated paper dust, ink, etc.).
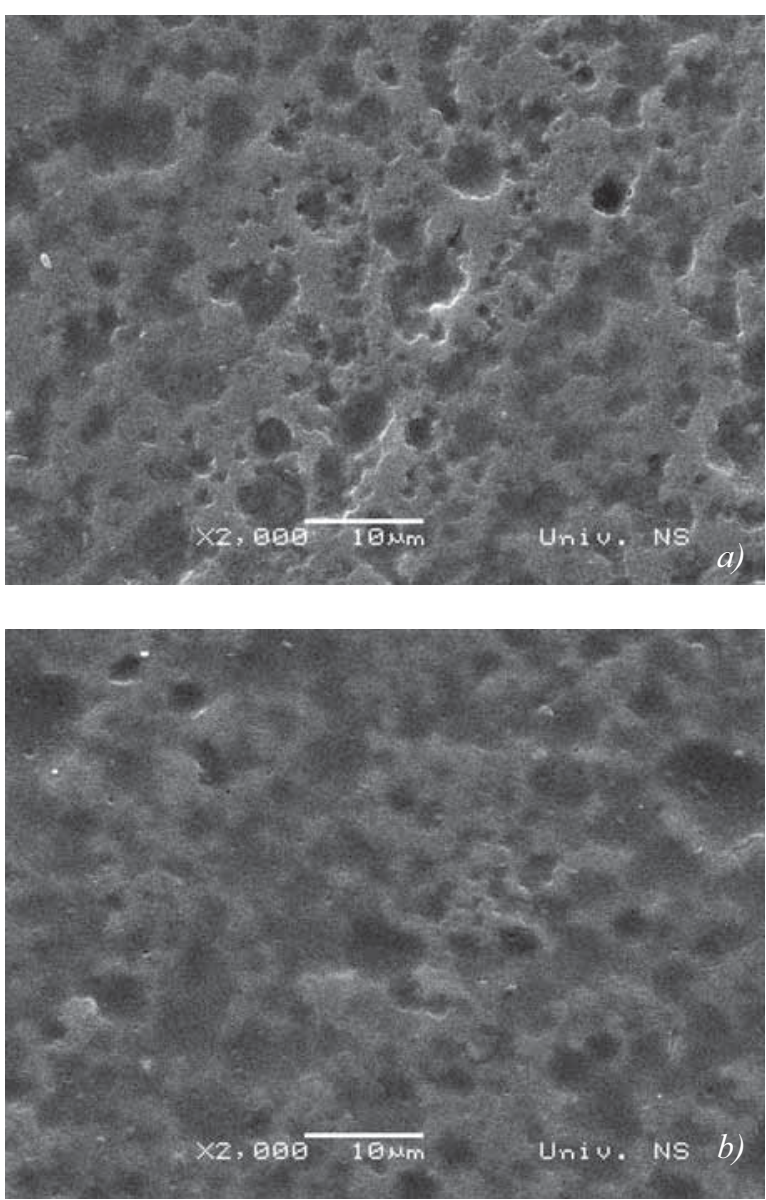

Figure 3. SEM micrograph of printing plate samples after 177.000 impressions of a) printing plate for cyan colour b) printing plate for yellow colour

On Figure 4 samples of printing plates after 300.000 impressions are shown. Longer print run and multiple pressure application can considerably affect on the surface properties and result is flattening of the surface and smoothening of peaks and other features, as it is shown of Figure 4 on SEM micrographs a) dust and particles can be seen on the surface of the printing plate. This printing plate was used for cyan colour from the second printing unit and these particles might be accumulated through the unbalanced relation between fountain solution and ink between first and second printing unit. On the micrograph b) sample for yellow printing plate from the last printing unit, worn surface with more closed/filled pores and ,valleys” is noticeable.

This change in surface topography reflects the process of sealing the surface pores and dissolution of peaks resulting in corresponding changes of surface profiles. Although the SEM micrographs provide an excellent tool for visualization and qualitative description, the changes of the surface topography are reflected in measurement of corresponding profilometric parameters. 

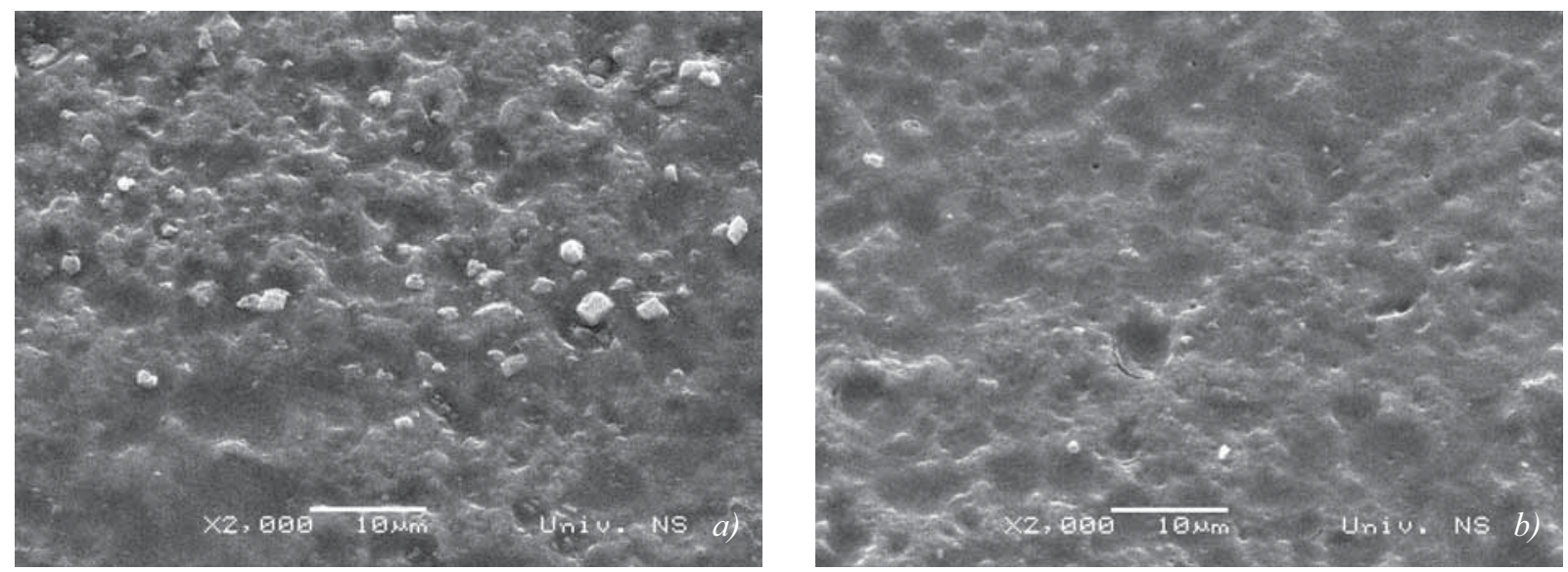

Figure 4. SEM micrograph of printing plate samples after 300.000 impressions of a) printing form for cyan colour b) printing form for yellow colour

\section{Measurement of the roughness parameters}

Changes in surface topography of the printing plate result in changes of the corresponding roughness profiles and it is indicated trough the profilometric parameters depicted in Figures 5-8.

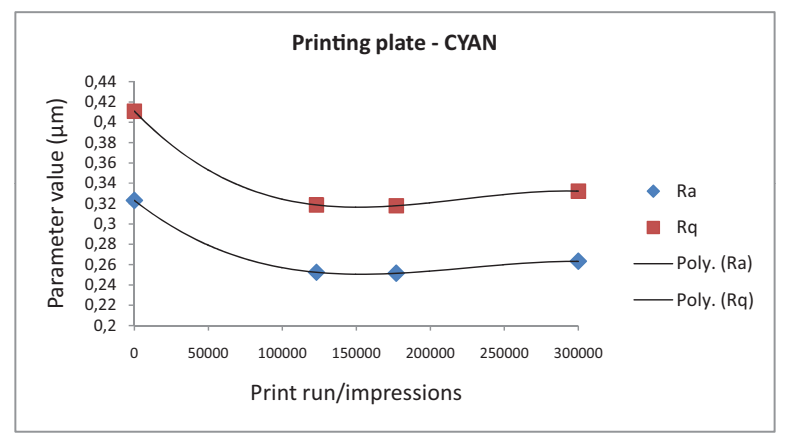

Figure 5. The change of profilometric parameters $R_{a}$ and $R_{q}$ for cyan printing plate $v$ s. the number of impressions
Parameters $\mathrm{R}_{\mathrm{a}}$ and $\mathrm{R}_{\mathrm{q}}$ (Figure 5) show same trend of measured result. Although we used a polynomial trend line to illustrate fluctuation of measured parameters, measured values also show decay with number of imprints. With a number of imprints $\mathrm{R}_{\mathrm{a}}$ parameter decreases and after approximately 120.000 impressions it is stabilized until the end of print run. From starting values of unused printing form until 123.000 impression, $\mathrm{R}_{\mathrm{q}}$ parameter has decay of $22,5 \%$ which is 0,6 $\%$ higher than decreasing of $\mathrm{R}_{\mathrm{a}}$, but also come to the stabilized values after certain period of print run.

The changes of the $R_{p}$ and $R_{z}$ parameters (Figure 6) and their values show similar trends between each other. Stabilization of the $\mathrm{R}_{\mathrm{p}}$ and $\mathrm{R}_{\mathrm{z}}$ parameters is after approximately 180.000 copies. From starting values of unused printing form until 180.000 impressions, decay of $\mathrm{R}_{\mathrm{p}}$ parameter is $28,3 \%$ and for $\mathrm{R}_{\mathrm{z}}$ is $28,94 \%$. After print run of 300.000 impressions values of the $R_{p}$ and $\mathrm{R}_{\mathrm{z}}$ parameters rising close to the measured value of un-

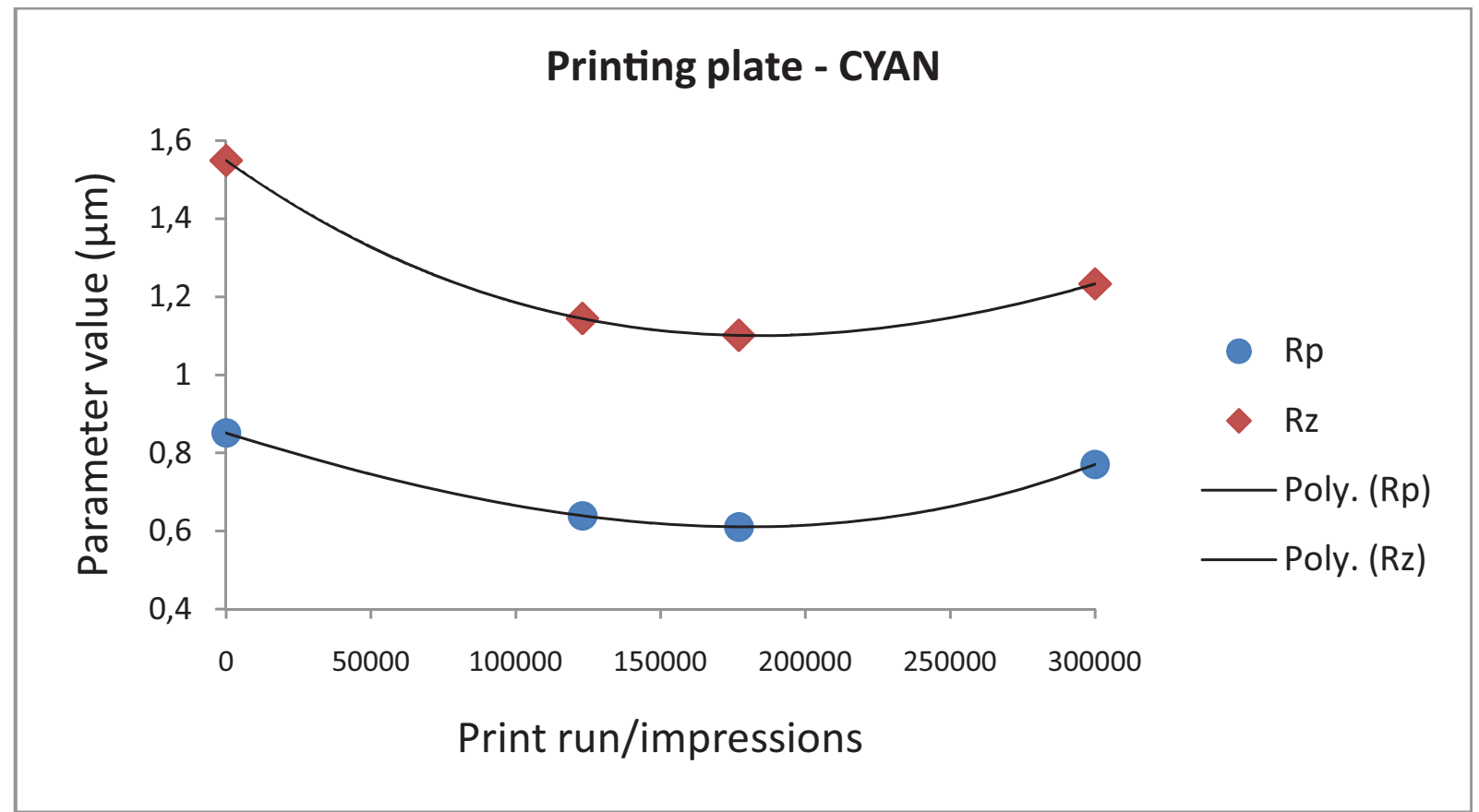

Figure 6. The changes of profilometric parameters $R_{p}$ and $R_{z}$ for cyan printing plate vs. the number of impressions 
used printing form, especially in case of $\mathrm{R}_{\mathrm{p}}$ parameters. Until stabilization, a relatively fast reduction of prominent sharp peaks with increased number of copies is reflected.

Parameters $\mathrm{R}_{\mathrm{a}}$ and $\mathrm{R}_{\mathrm{q}}$ for yellow printing form (Figure 7) show more variations during print run in comparison with same parameters for cyan printing form. These parameters have significant decay of the measured values between unused sample and print run of 100.000 copies. The $\mathrm{R}_{\mathrm{a}}$ parameter has decay of $20,7 \%$ which is only $0,1 \%$ higher than decreasing of $\mathrm{R}_{\mathrm{q}}$. It means that surface peaks with sharp ends become quickly re- duced and the ,valleys” are closing slowly. After approximately 120.000 impressions measured values of $\mathrm{R}_{\mathrm{a}}$ parameter is stabilize with a increase of $6,4 \%$ until 300.000 copies.

$R_{p}$ parameter show decay of $19,9 \%$ and that's $3,9 \%$ lower than decreasing percentage of $\mathrm{R}_{\mathrm{z}}$ parameters. Stabilization trend of values begin after approximately 130.000 copies of the $R_{p}$ and $R_{z}$ parameters (Figure 8). Trend for $\mathrm{R}_{\mathrm{p}}$ parameters for cyan printing form, after stabilization period until end of the print run, has rising value of $20,8 \%$ in comparison with yellow printing form value of $\mathrm{R}_{\mathrm{p}}$ parameters, which has decreasing of

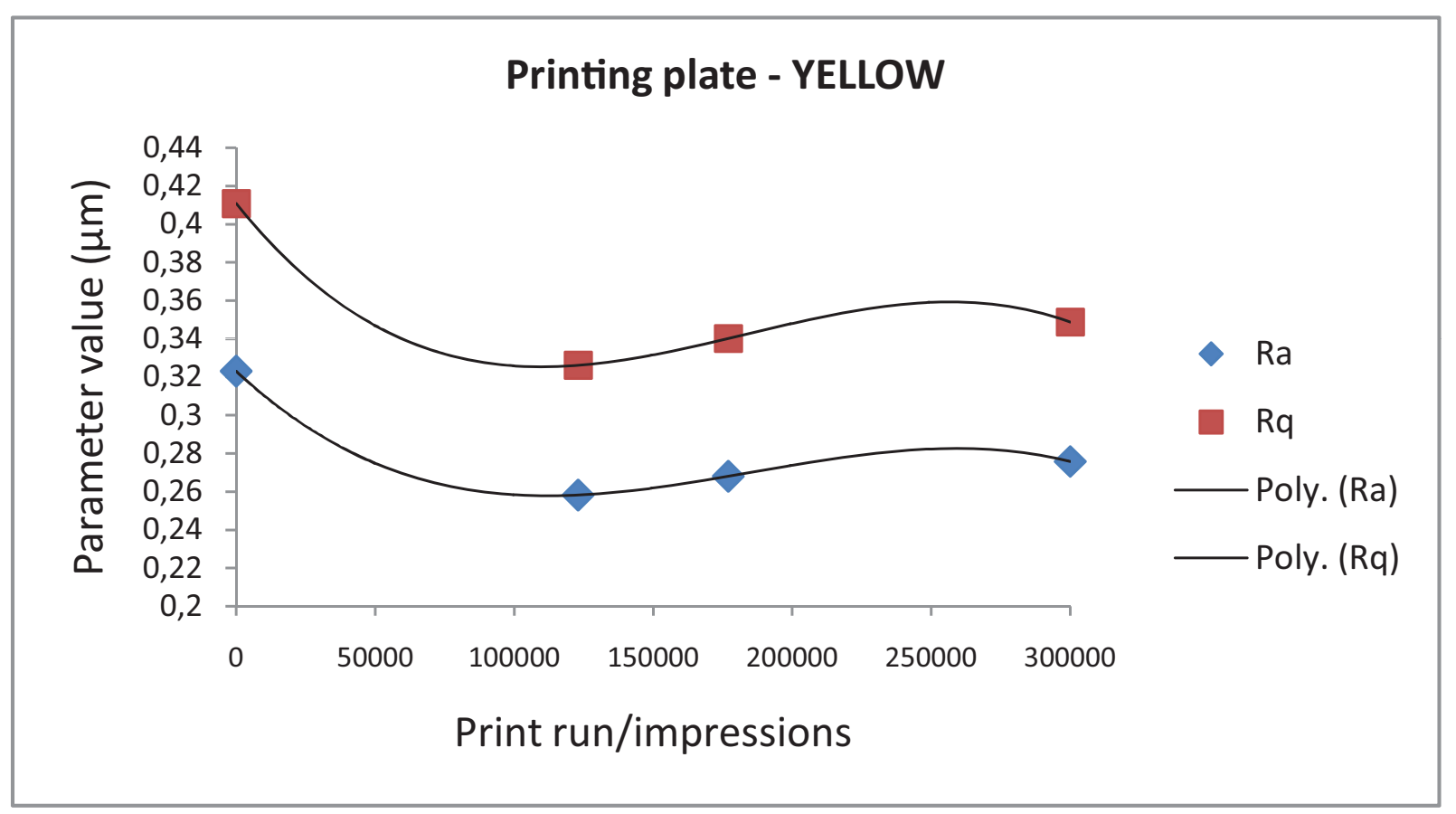

Figure 7. The changes of profilometric parameters $R_{a}$ and $R_{q}$ for yellow printing plate $v$ s. the number of impressions

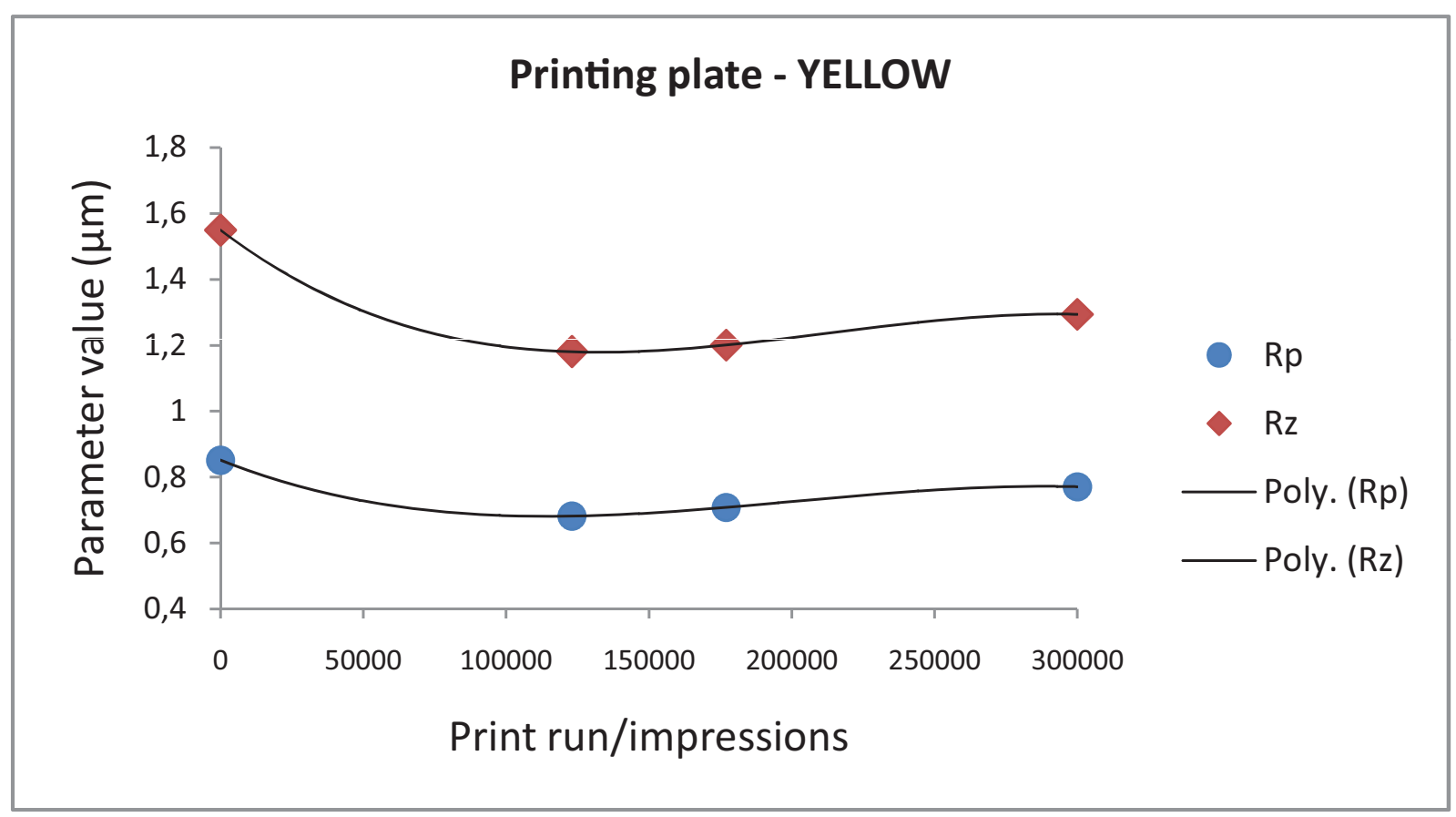

Figure 8. The changes of profilometric parameters Rp and Rz for yellow printing plate vs. the number of impressions 
$8,8 \%$. This results show opposite trends for $\mathrm{R}_{\mathrm{p}}$ parameters of these two printing forms.

Presented results should be considered only as rough estimates while only four reference samples have been used. More accurate and exact trend lines could be obtained if more points, especially at the beginning of print runs, were used for the polynomial or exponential decay fit.

\section{Conclusions}

With the SEM micrographs were provided visual and qualitative description of the non-printing elements, but the physical changes of the surface topography were reflected on measurement results of corresponding profilometric parameters. The obtained results of surface roughness for both printing plate samples maintain similar trends and shows estimated percentage difference between the different parameters. Profilometric characterization and surface roughness of non-printing elements of printing form in order to determine changes of aluminium oxide surface influenced by print run of 300.000 impressions have been investigated.

Physical and geometrical changes of the surface topography caused by a print run of 300.000 might have influence on the stability of aluminum oxide layer and thus on photosensitive layer known as printing elements. Therefore, investigation on formation of different porous structures of aluminium oxide and their influence of the fountain solution adsorption could be based on obtained results and can be used for further research in these fields.

\section{References}

1. Anon. (2009) TR200 Surface Roughness Tester. [Online] Avaliable from: http://www.portabletesters.com/Products/SurfaceRoughnessTesters/ TR200SurfaceRoughnessTester.aspx [Accessed 16 March 2009]

2. Brinkman, H.J., Kernig, B. (2003) Aluminium for lithographic applications. [Online] Avaliable from: http://aluminiumcentrum.nl/aluminiumcentrum.nl/ files/Doc/Congres\%202006/module\%20c/1-Dr. Henk-Jan_Brinkman.pdf [Accessed 16 March 2009]

3. Dimogerontakis, Th., Van Gils, S., Ottevaere, H., Thienpont, H., Terryn, H. (2006) Quantitative topography characterization of surfaces with asymmetric roughness induced by AC-graining on aluminium. Surface and Coatings Technology, 201(3-4), 918-926.

4. Hutchinson, R. (2001) Surface engineering for lithography : a series of compromises. Transaction of the Institute of Metal Finishing, vol. 79 (4), pp. 57-59
5. International Organization for Standardization (1996) ISO 4288:1996. Geometrical Product Specifications (GPS) -- Surface texture: Profile method -Rules and procedures for the assessment of surface texture. Geneva, ISO.

6. International Organization for Standardization (1997) ISO 4287:1997. Geometrical Product Specifications (GPS) -- Surface texture: Profile method -Terms, definitions and surface texture parameters. Geneva, ISO.

7. International Organization for Standardization (1997) ISO 12218:1997. Graphic technology -- Process control -- Offset platemaking. Geneva, ISO.

8. International Organization for Standardization (2004) ISO 12647-2:2004. Graphic technology -- Process control for the production of half-tone colour separations, proof and production prints -Part 2: Offset lithographic processes. Geneva, ISO.

9. Mahovic Poljacek, S., Gojo, M., Raos, P., Stoic, A. (2007) Different Approach to the Aluminium Oxide Topography Characterisation. In: Touratier, M., Chinesta, F., Cueto, E. and Doblare, M. (eds.) 10th ESAFORM Conference on Material Forming, AIP Conference Proceedings, 18 20 April 2007, Zaragoza, Spain. Melville, AIPPress. pp. 64-69.

10. Mahovic Poljacek, S., Cigula, T., Gojo, M. (2008) Formation and Defining the Different Aluminium Oxide Microstructures in Alkaline Solutions. International Journal of Material Forming, 1 (1), pp. 463-466

11. Mahovic Poljacek, S., Risovic, D., Furic, K., Gojo, M. (2008) Comparison of Fractal and profilometric Methods for Surface Topography Characterization. Applied Surface Sciense, 254 (11), pp. 3449-3458. 